\title{
Teaching Games for Understanding: A Comprehensive Approach to Promote Student's Motivation in Physical Education
}

\author{
by \\ David Hortigüela Alcalá1, Alejandra Hernando Garijo ${ }^{1}$
}

\begin{abstract}
It seems important to consider students' attitudes towards physical education (PE), and the way they learn sports. The present study examines students' perceptions of motivation and achievement in PE after experiencing three consecutive sport units. Two hundred and thirty seven students from the 1st, 2nd, 3rd, and 4th grade in a high school in Burgos (Spain) and two teachers agreed to participate. They were divided into two groups in order to compare two instructional approaches. The experimental group $(A), 128$ students, experienced Teaching Games for Understanding (TGfU), while the control group (B), 109 students, experienced a technical-traditional approach. Each group was taught by a different teacher. The study followed a mixed-method research design with quantitative (questionnaire) and qualitative (interview) data. Results revealed that group A showed greater motivation and achievement in PE than group B. Significant differences were found in achievement. Participants with better academic results in group $A$ were more positive in sport participation. Meanwhile, students who practiced more extracurricular sports in group B were more actively involved in sport. Teachers disagreed greatly on the way sport should be taught in PE.
\end{abstract}

Key words: methodology, motivation, perception of achievement, teaching models, mixed methods.

\section{Introduction}

Sport is an essential and important feature of society, becoming a phenomenon closely linked to social, cultural and educational elements (Mackintosh and Liddle, 2015). In schools, sport defines hobbies and relationships (Wellard, 2012). Physical Education (PE) is directly linked to students' positive perceptions and sport habits. Games and sports are important aspects of the subject. However, teachers' methodological approaches will determine student's motivation to perform extracurricular sport (Casey and Quennerstedt, 2015). Therefore, PE can play an important role in generating greater commitment to sport (Hortigüela et al., 2016), yet it depends on the pedagogical models used in class and the assessment strategies used to involve students. Coulter and Ní Chróinín (2013) indicate that if PE does not focus on student's learning, it will be difficult to generate understanding, learning and student's satisfaction. Therefore, it is necessary to consider essentials such as physical self-concept, self-improvement, promotion of interpersonal relationships and positive group climate development (Hortigüela et al., 2016). All of the above place a lot of responsibility on the teacher, since their teaching can influence the connections between the body use and student's personality, affecting their involvement in the subject, physical activity practice and motor goals (Hortigüela et al., 2016a). Some variables have been described as decisive: learning units, pedagogical approach, tasks and teacher coordination to give continuity to sport learning (Coulter and Chroinin, 2013). This is very important as $60 \%$ of students recognize that $\mathrm{PE}$ is the only physical activity they perform. Therefore, experiences in PE can influence lifelong participation in sport.

Teaching Games for Understanding (TGfU)

1 - Teaching of Corporal Expression Area, Specific Didactics Department; Faculty of Education, University of Burgos, Spain. 
is a pedagogical model which originated in the 1980s with the main objective of promoting learning in sport (Thorpe et al., 1986). It prioritizes understanding tactics and play over technique. There are different published experiences on the implementation of this model in various sports (Hastie and Curtner-Smith, 2006; MendezGiménez et al., 2012; Roberts, 2011). However, its use in PE is still limited (Diaz-Cueto et al., 2010). When teachers do not obtain positive results in the short-term, they are not patient enough and go back to traditional approaches (Hopper, 2002). Other experiences have shown that TGfU increases positive transference to other PE contents, and, consequently, to physical activity practice (O'Leary, 2016; Stolz and Pill, 2014). It is its constructive character which allows the use of games as a learning tool to develop social values (O'Leary, 2016). Finally, Mesquita et al. (2012) showed that the implementation of TGfU improved both students' decision capacity and motor skills in different contexts.

Most of the published experiences on TGfU focused on its ability to help students understand game play. There are few longitudinal studies that evaluate motivation and achievement from the students' perspective. This constitutes the main contribution of this study. The research objectives were: 1) to assess the impact of TGfU on student's motivation and achievement in sport; 2) to study how variables such as grades, academic results, and extracurricular sport practice influence student motivation and interest in sport, and 3) to contrast PE teachers' perceptions on the importance of methodology to teach sports.

\section{Methods}

\section{Participants}

There were 237 participants in the study (58.3\% males, $41.7 \%$ females), who were students from a secondary school in Burgos (Spain). Sixtythree were in the $1^{\text {st }}$ grade, 64 in the $2^{\text {nd }}, 56$ in the $3^{\text {rd }}$ and 54 in the $4^{\text {th }}$ grade. The average age was $13.32 \pm 2.31$ years. Two groups were naturally created. The experimental group (A), 128 students (35 1 $1^{\text {st }}, 312^{\text {nd }}, 303^{\text {rd }}, 324^{\text {th }}$ grade), experienced TGfU. None of the students had experienced this pedagogical approach before. The control group (B), 109 students $\left(281^{\text {st }}, 332^{\text {nd }}, 263^{\text {rd }}, 224^{\text {th }}\right.$ grade), experienced the traditional approach. Participants were selected by convenience.
Two teachers agreed to participate in the study. The teacher of group A had 6 year experience in secondary education, with this being his first year in the school where the study took place. The teacher of group B had 26 year experience in secondary education and had worked seven years in the school. Based on their previous knowledge, each of them was responsible for teaching one of the two instructional approaches: the teacher of group B, the technical-traditional instruction, and the teacher of group A, TGfU.

In order to improve the knowledge of teacher A on TGfU, she was asked to attend a $30 \mathrm{~h}$ seminar given by a university professor with more than 8 year experience in theory, practice and research on TGfU. The goal was to learn games, tasks and pre-designed lessons for practice, analysis and discussion to be able to design the final version of the learning unit to be implemented. During the execution phase of the project, the teacher and the university researcher regularly shared their views, problems and solutions in order to increase their knowledge and interaction with one another.

\section{Design and procedures}

The study design was quasi-experimental comparing equivalent groups (natural groups). Participants were therefore not randomly chosen. A pre- and post-test were performed on each group to assess the influence of the methodology used on student's motivation and achievement in PE. This type of the design raises two questions (Campbell, 1988): internal validity: natural groups (from regulated schools) were used, and external validity: explaining in detail the procedure to be followed. This ensures that the study can be applied in similar schools and using a larger sample.

To begin the research, permission from the Ethics Committee of the main investigator University and from the educational center was obtained. Subsequently, informed consent from participating students' parents was obtained. Finally, students completed a questionnaire anonymously during a PE lesson (before and after implementing the three sport units). We encouraged them to answer the questions as honestly as possible and we assured them that their answers would not affect their marks in PE. Interviews with teachers were carried out at the 
end of the term, once they had finished the three sports units.

\section{Instructional Intervention}

Both groups received three team sports units in the first term. Contents included basketball, floorball and handball. Every unit lasted eight lessons, so the intervention phase was 24 lessons. Sports were the same for all levels (1 $1^{\text {st }}$, $2^{\text {nd }}, 3^{\text {rd }}, 4^{\text {th }}$ grade), but a different progression and sequence of activities were established for each grade. The main objective of the intervention was to understand the structure of the game for each sport and the ability to play independently. Group A received the TGfU methodology, while group B followed the model of technical teaching.

The structural design of group A followed the essential characteristics of the model (Kirk and MacPhail, 2002) A) Transference: different skills between sports using common teaching sequences, B) Representation: adapting the sport structure to the student's needs, C) Exaggeration: changing tactical elements in a task to make them more visible, D) Increasing tactical complexity: to facilitate its understanding, and E) Authentic assessment: conducting it in real game situations. All TGfU learning units followed the same structure ( $\mathrm{O}^{\prime}$ Leary, 2016): 1) Play: a game was modified to promote students' participation and interaction, 2) Tactical awareness: teacher and students worked on tactical elements, and 3) Ability execution: selecting the technical elements necessary to perform the tasks. Each lesson was completed in 55 minutes. Priority was given to understanding tactical aspects, the game itself, reflection on errors and acquired learning. Responsibility during the process was high, but there were no technical elements that limited practice. The relationships between the students were of great importance, showing that enjoyment outweighed performance. The modifcation of rules was allowed applying them to real game situations and contexts. A formative assessment process was essential, stimulating student's capacity. Grouping varied in order to encourage playing with and against everybody in the group. Transference between different sports was sought. In the first sessions, the students began playing the sport directly. Subsequently after detecting the erroneous elements in each of the groups, situations of offensive and defensive superiority were established applying what had been learned. In the three sports, each working group had to record the improvements in their journal. The aim was to practice sport games in later sessions in order to integrate them in game situations. At the end of each session, a "conditioned game" was practiced, including the technical and tactical aspects performed. Teachers gave weekly reports about the work done by each of the groups, evaluating the various sport games that were developed. In addition, peer assessment was allowed, using each group's graphical representation to explain the work to their peers.

Group B followed the traditional technical instructional approach that is most widely used in PE. It is based on the development of technical skills and teacher-centred decisions; some authors call it direct instruction (Metzler, 2005). Each lesson includes an initial warm-up, skills, techniques and tactics of the sport in the central part, and a game at the end (Siedentop and Tannehill, 2000). The teacher is responsible for every aspect of the lesson. Students only participate and perform (Wirszyla, 2002). Student groups change daily, and they are selected by the teacher. He/she keeps total control of the class (Hastie, 1998). Teachers referee during games or matches. The methodology emphasizes the acquisition and mastery of previous technical gestures. Later, technical gestures are applied to tactical situations. No reflection on the game as a learning tool is used. Trial and error are used as elements of increasing complexity. Responsibility of the students in the understanding and development of each game is of great importance, yet this is not implemented throughout the teaching process. Real game situations are proposed from the beginning based on the original regulation of disciplines. Major corrections are made to technical tasks before matches. Every sport has its specific technical elements.

\section{Research variables}

The dependent variables of the research coincided with the two factors extracted in the quantitative part. These factors included motivation towards PE and achievement perception in PE. The independent variable was the methodological approach used by the PE teacher. In the ANOVA, interest in the sport was used as a dependent variable, while academic results, grade and extracurricular sport were 
considered independent variables. These variables were in line with the objectives of the study and techniques used in data analyses. Qualitative data was structured to match the dependent variables. In this respect, we used the same qualitative variables as study factors derived from questionnaires: 1) student motivation toward physical education, and 2) achievement of students in physical education. This would enable further research and contrast the perception of students and teachers on these variables, thus justifying their internal validity.

\section{Instruments}

\section{Quantitative}

The Questionnaire to measure motivational strategies in physical education lessons (QMSPE; Cervelló et al., 2007) was used in this research. It was composed of 24 items that measured two dimensions: 1- task climate (12 items; i.e., item 9: "He/she encourages us to progress and improve") and 2- ego climate (12 items; i.e., item 15: "He/she only cares about best students"). It was valued on a Likert scale from 0 (strongly disagree) to 10 (strongly agree). Questions were preceded by the following introduction: "In physical education lessons...". A high FC $=.91$ and VME greater than $.50(51.03 \%)$ were obtained. The Cronbach Alpha reliability parameter was controlled to measure the reliability of factor analysis and this value was found to be .82 , exceeding the lower limit according to Corbetta (2007). It was accepted by applying a level of confidence of $95 \%$. Omega reliability was 69 .

The $2 \times 2$ achievement goals in physical education scale (Moreno et al., 2008) was applied. It was composed of 12 items that measured four different aspects: 1-performance-approach (3 items; i.e. item 1: "It is important for me to do it better than other students") 2- mastery-approach (3 items; i.e. item 6: "It is important for me to understand the subject content as much as possible"), 3performance-avoidance (3 items; i.e. item 3: "I just want to avoid doing it wrong"), and 4- masteryavoidance (3 items; i.e. item 8: "I often worry about not being able to learn everything I need"). It was valued on a Likert scale from 0 (strongly disagree) to 10 (strongly agree). Questions were preceded by the following introduction: "In physical education lessons...". A high FC $=.92$ and VME greater than $.50(58.87 \%)$ were obtained. Cronbach Alpha reliability parameter was controlled and this value was found to be .82 , exceeding the lower limit according to Corbetta (2007). Omega reliability was .67 .

A factorial analysis of principal components was performed in order to check the adequacy of the questionnaires to the sample used. The exploratory factor analysis revealed a solution of two factors with self-worth superior than one. Both factors explained the variance, once corrected and rotated matrix components (normalized Varimax). The initial self-worth for the first factor corresponded to $47.218 \%$ of the variance, while the second to $32.519 \%$ of the variance. In order to evaluate the goodness of fit, a confirmatory factor analysis of the main components was carried out. Appropriate values for the Kaiser-Meyer-Olkin (KMO) index (.818) as well as in the Bartlett's sphericity test $(p>.01)$ were obtained. This test showed a value of Chisquare of 134.262 and 12 degrees of freedom. The indices obtained in the covariance matrix presented satisfactory adjustments to the RMSEA index $($ Root Mean Square Error Aproximation $)=.067$. In this index, values less than .05 indicate a good fit and values up to. 08 represent reasonable errors of approximation. In the CFI (Comparative Fit Index), GFI (Goodness of Fit Index) reached a value of 0.9 and 0.93 , which is indicative of a good fit. In addition, a value of 0.92 in the TLI (TuckerLewis Index) was obtained.

Similarly, each item was individually validated and for this purpose, the regression coefficient was used. The value of $\mathrm{T}$ associated with each estimation was used as a contribution measure. This value is the quotient between the estimate parameter without standardizing and the standard error (regression ratio). Values greater than 2.00 were considered significant, resulting in a value of 2.19. The confirmatory factorial analysis revealed two final factors for the study:

1- Student's perception of his/her motivation in PE (24 items): items related to the student's evaluation of the subject and the role he/she plays in it. Explanations, corrections, and responsibility of tasks were considered (i.e., "They let us take part in the organization of activities").

2- Student's perception of achievement in PE (12 items): this included factors related to performance, learning, skills control, insecurities and the importance given to 
task resolution (i.e. "It is important for me to perform well compared with others").

Qualitative

Qualitative information extraction was performed through a semi-structured interview of the two teachers participating in the research. The objective was to explore the interviewee's thoughts to get an insider's perspective on their professional practice (Patton, 2002). Based on this idea, a script was developed taking into account researchers' knowledge and similar research. As the nature of the interview was semi-structured, researchers were able to add new questions based on the answers to turn the interview into a conversation (Patton, 2002). This open format allowed us to explore new areas and produce richer data. According to the variables of the study, participants were asked about six aspects after finishing the three sports units (Table 1).

All information related to these responses was grouped into two categories for further analysis: 1- student's motivation towards physical education, 2- student's achievement in physical education.

These two categories were generated based on the triangulation process and saturation of information obtained in the interviews with two teachers. The theme of the interview questions was designed from these categories, allowing for a more powerful interplay of information. In addition, this interview was configured from the information from the two questionnaires and the two factors studied in the quantitative part. This linearity and consistency between data collection instruments of quantitative and qualitative parts ensured the reliability of mixed methods.

\section{Analysis}

All data was analyzed using a mixedmethod approach via Repeated Measures Analysis of Variance (RMANOVA), descriptive statistics and qualitative methods. Using this approach, it was possible to determine the influence that teaching methodology had on student's motivation and their perception of achievement in sport. A pre- and post-test were used. Furthermore, teacher interviews were applied at the end based on common categories. This processing of data would provide greater understanding of results obtained. It also favoured the transformation of educational processes. It is necessary to clarify that we analyzed observations by levels, making sure that there was no constant variance problems which altered the assumption of normality.

Quantitative

Data was analyzed using a mixed-method approach via Repeated Measures Analysis of Variance (RMANOVA) for independent groups in order to check changes in student's perceptions after the intervention process. The ANOVA was used to analyze how variables such as academic results, grade and out-of-school sport practice influenced sport motivation in each group studied. The obtained data was analyzed using the SPSS 22.0 statistical package program. In order to define the distribution of data, the One Sample Kolmogorov-Smirnov test was applied $(\mathrm{n}>50)$ accepting the null hypothesis at $p=.187$. Accordingly, the data showed a normal distribution in both groups.

Qualitative

There is a direct linearity between quantitative and qualitative analysis. The researcher adopted a semi-structured interview for teachers participating in the research. Extracted data was analyzed through analysis of content (Libarkin and Kurdziel, 2002) and comparison between data. The analysis of content focused on searches for patterns in text, encoding extracts with cross patterns (Saldana, 2009). The objective was to use the information obtained to give greater comprehensibility. The two categories are clearly shown in the results section with the support of several examples of text extracts. WEFT QDA software was used to analyze the qualitative data. Open encoding with emerging categories was carried out. The use of axial coding for categories and selective coding led to the development of an interpretive model. After importing the two interviews to the program, the categories were generated based on their subject matter. Text was assigned to each category, which subsequently promoted its codification through saturation of information. This process was carried out consistently, ensuring specificity and reliability. The fact that the variables were the same in the quantitative and qualitative part eliminated the possibility that they overlapped research. It is worth noting the opinions of the teachers participating in the experiment. The two teachers taught the two groups in the three units, and therefore had 
knowledge of the behavior and motivation of the students.

Every text extract was identified with one of the defined categories, which favoured saturation of information. The acronym used for the teacher who used the TGfU was DTGU and for the teacher who carried out the technical sport methodology was DMDT.

The interviews were audio-recorded in order to later transcribe all the information and import it to the software. The two interviews were reviewed in depth by researchers, creating the categories of analysis based on their direct relationship with both quantitative factors. Initially, five general categories emerged. Each investigator assigned specifically extracted texts to each of the categories, which were subsequently reviewed by other researches. This process of triangulation of the data allowed us to obtain the most reliable information, especially when there a previous quantitative part. Once encoded, the data crossed between them, selecting more saturated text extracts, which were representative of the methodology used by the PE teacher.

\section{Results}

\section{Pre- and post-test differences in groups in two} study factors

It can be observed how pre-test values reached similar averages in two factors from each group, and in all cases exceeding the value of 7. In group A, post-test values increased in both factors, showing significant improvements in PE motivation. The effect size of the obtained .92 is considered to be high. However, there were no significant differences in group B after the intervention, producing a decrease in students' perception of achievement in PE. There is a significant difference in the post-test between both groups in factor 1, which was motivation, being higher in the group which received the TGfU methodology.

\section{Inferential analysis: ANOVAS}

Taking into account the differences found between the pre-test and post-test on two study factors in each group, the variable named "interest in sport" was generated. This variable was used as a dependent variable. ANOVA was used in order to check whether there were statistically significant differences in students' interest in sport based on independent variables such as educational centre, number of students per class and grade. In addition, a post-hoc analysis was carried out indicating in which group that difference was found.

The first variable includes academic results, according to the number of failed subjects in the first term; 1 - no failed subjects, 2 - between two and three failed subjects, 3- more than three failed subjects. The second one is the grade categorized as: 1- first grade, 2- second grade, 3- third grade, 4- fourth grade. The last one refers to extracurricular sport practice; 1- nothing, 2between one and three hours per week, 3- more than three hours a week (Table 3).

Significant differences in the academic results variable were observed in group $\mathrm{A}$ as students from this group had not failed any subject in the first term and showed a greater interest in sport $(\mathrm{F}(237)=103.31, p=.033)$. In group $\mathrm{B}$, differences were found in the extra-curricular sport practice variable, showing a greater interest in sport of students who practiced more than three hours a week out of school. The grade did not influence significantly the interest in sport in any group.

\section{Qualitative analysis}

All information extracted from interviews produced some main categories:

1- Student's motivation towards physical education (256 text excerpts). Two teachers had a different perception of the student's motivation in class. The teacher of the experimental group valued an increase in student's motivation towards the subject over time, stating that the methodology used and the role of teachers was key to this motivation:

"It shows how the methodology promotes student's motivation [...]". "At the beginning of the course students were not involved in sport practice [...]. However, during the term the students made their own rules and proposed alternatives to activities [...]." "I think student's motivation towards physical education depends largely on the role of the teacher and the methodology he or she uses in the classroom. It cannot be expected that the student is already motivated from the start". (DTGU).

However, the control group teacher did not give too much importance to the methodology. He believed that motivation was a little more personal and less modifiable factor by the context: 
"Motivation is very different in students. I think that it is personal to each student and goes according to their personality and their evolutionary development [...]". "I have been using the same methodology for some time and some students are more motivated than others. There are also many changes between the different years. The interests of the students change every year, but I don't think that we should change the content in class [...]. The most important thing is to do sport, and unfortunately students are increasingly sedentary". (DMDT).

2- $\quad$ Student's achievment in physical education (248 text excerpts). In line with the previous variable, again the two teachers had different views. The teacher of the experimental group tried to make sure that all students achieved the tasks proposed in the class:

"It is impossible to satisfy students if they themselves do not feel competent [...]". "Only when students are able to understand what we are offering, will they want to return to try new challenges and objectives [... ]." "To do this, these comprehensive sport methodologies are key, since no one is excluded because of their fitness levels. The rules are adapted and they accept their limitations and capabilities, but they always achieve success". (DTGU).

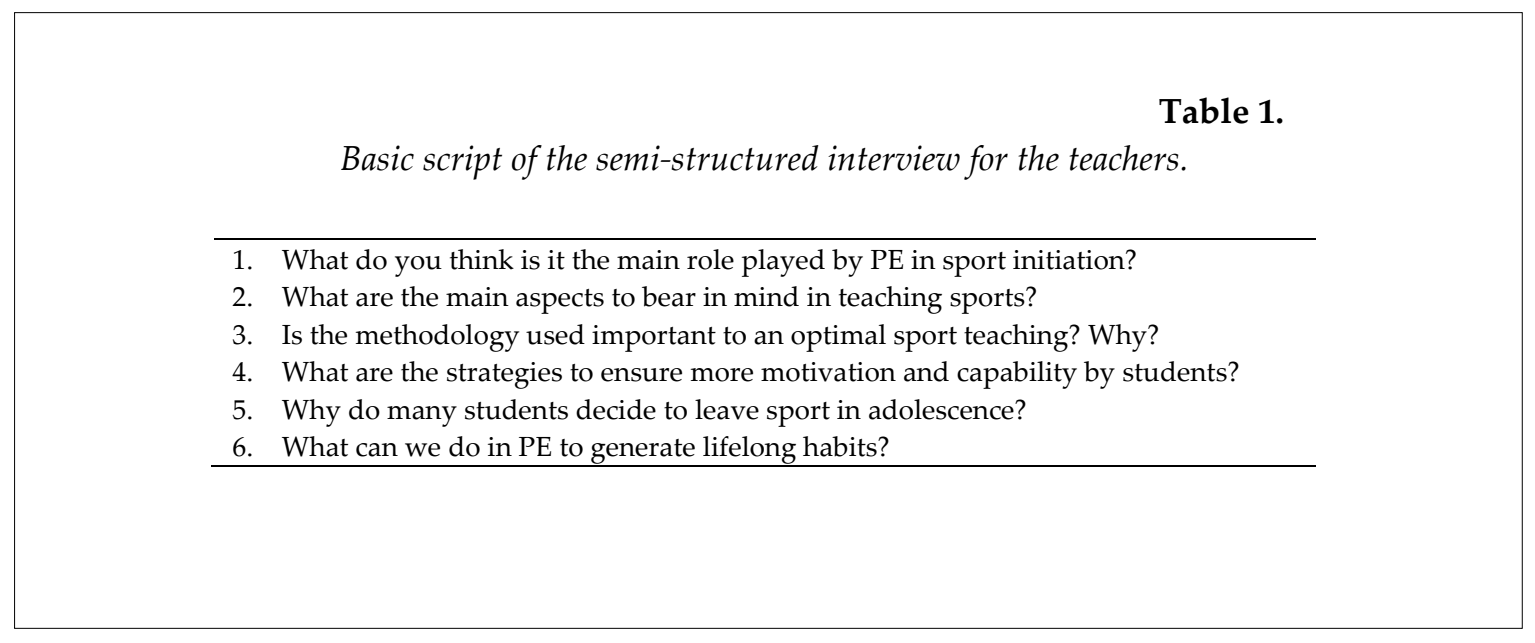

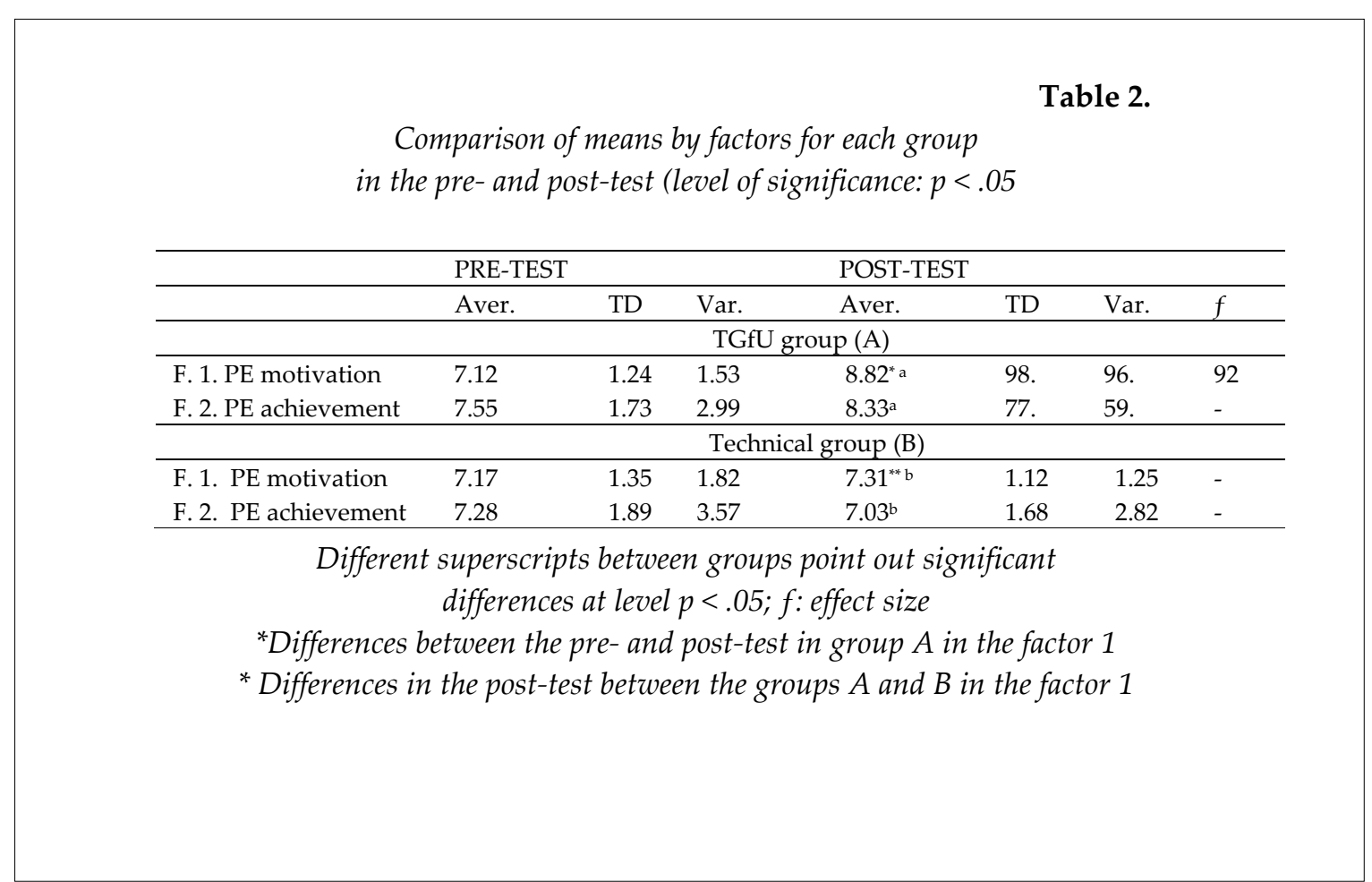




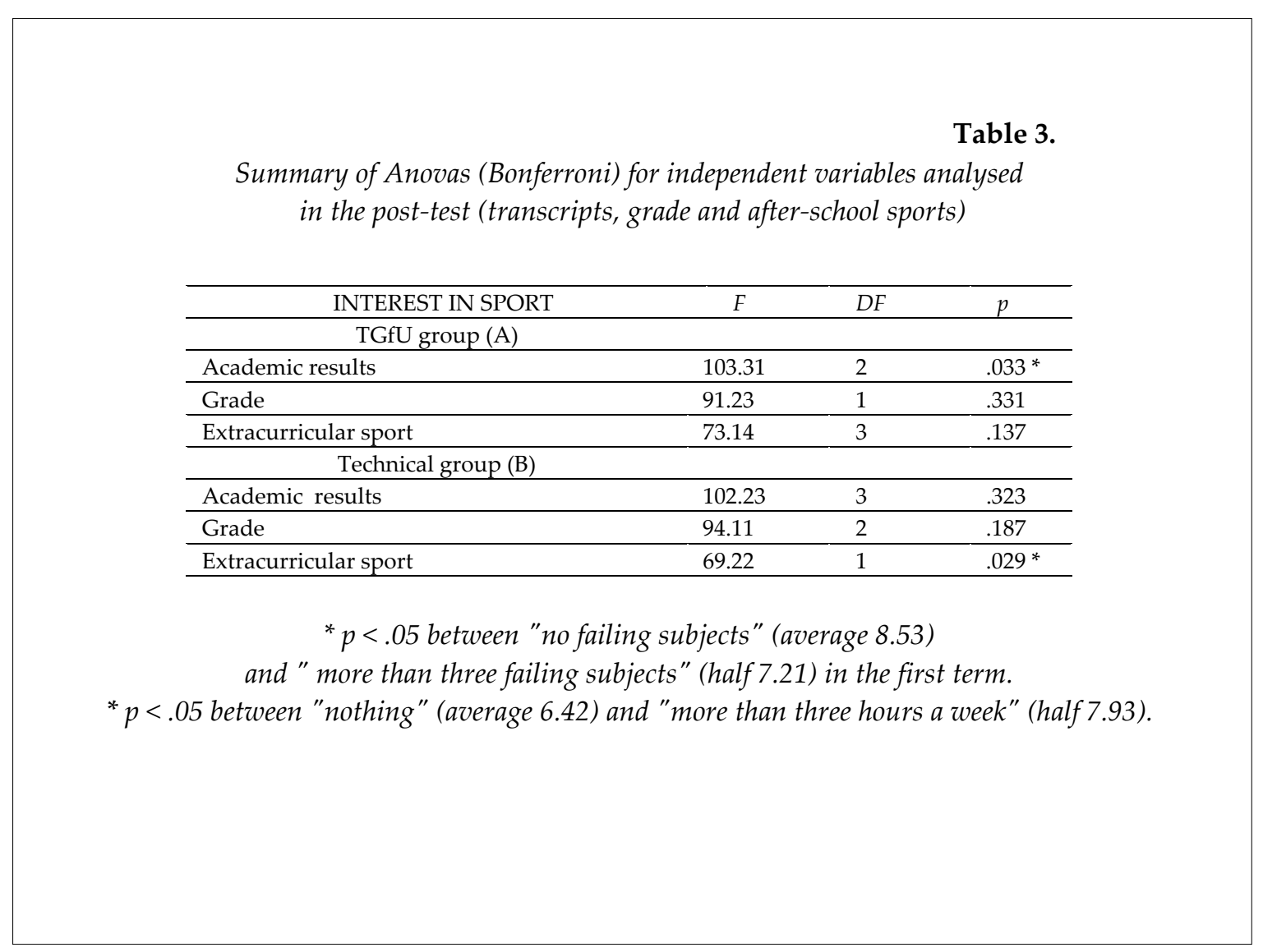

However, the control group teacher said that we must remain realistic:

"We have to be realistic, we cannot think that all our students are physically fit [...]. There are students with mixed levels of fitness, so some of them will have to accept the fact that there are activities that they will not be able to do." "Do we have to give them all a 10? [...]. Like in maths not all students have the same level, and nor do they in PE. I think it would be a mistake to lower the level of the subject. Because then we complain about the levels of obesity, but would we be doing anything about it?" (DMDT).

\section{Discussion}

The research reflects how the introduction of the TGfU methodology influenced the motivation towards sports practice. This increase was higher when compared to the technical teaching model. Within group A, students with the best academic results showed a greater interest in sport. In group B, the interest was higher in students who participated in extracurricular sport.
The greatest increase after the intervention occurred in student's motivation to physical activity practice, which reflected that TGfU was effective in this regard. It shows how open and participatory methodologies in PE lessons such as the attitudinal style produce improvements in student's involvement, positive class environment and a better self-concept (Hortigüela et al., 2016b,c). One aspect that characterizes TGfU is understanding and game knowledge, which promotes intrinsic motivation (Stolz and Pill, 2014). This line shows the relationship between the assessment used by the PE teacher and what students felt they learned. When assessment is associated with game situations in a real context, students' learning perception is more favorable than when assessment is only focused on physical or technical aspects (Arias-Estero and Castejón, 2014). O'Leary (2016) considers that one aspect that TGfU has added to PE is the possibility of modifying games to make them more achievable and interesting. There are also some improvements after its implementation in 
student's perception of achievement, a factor that decreased even in group A. This may be due to excessive initial technical requirements in group $\mathrm{B}$, a possible limiting factor for enjoying the activity. In this regard, experiences show how reflection and modification of technical, tactical and structural patterns of games make students more aware of its execution, while the teacher may present initial insecurities in the implementation of the model (Diaz-Cueto et al., 2010). Moreover, in TGfU, the responsibility of the student throughout the process of teaching and learning must be noted. This experience is essential in sports initiation, since what is really important is to focus on the understanding of the sport as a whole, not on the specific technical aspects (Hopper, 2002).

With respect to influential variables in interest in sports, in group A, students with the best results showed higher rating compared with those who had more than three failed subjects. Therefore, the TGfU methodology is associated with cognitive development, understanding and reflection on practice variables, which contradicts the idea of play by play and lack of learning in sport education (Butler, 2014). When students do not have a high level of motor performance, it is impossible to enjoy sports if they only reproduce technical gestures in isolated situations (Mesquita et al., 2012). In group B, differences were found in the extracurricular sport practice variable. Students who participated in more than three hours a week of extracurricular sports activity showed greater interest in sports. This result can be obtained beforehand, connecting different technical PE models. It contrasts therefore with the models of sports education used in many educational centers (Casey and Quennerstedt, 2015). This idea justifies the result obtained in the present investigation, evaluating how students who do not carry out extracurricular sports are more uncomfortable with technical teaching models. However, grades were not an influential factor regarding interest in sport in both groups. This differs from the results obtained in another study, which shows that females and younger students had more self-determined profiles than others (Sánchez et al., 2015).

The qualitative part of the study served to verify the information on the perception of students obtained in quantitative data. It is important to analyze the position of the two teachers regarding the role that the methodology plays in generating motivation and satisfaction in students towards PE. As for motivation towards physical education, the group A teacher highlighted the role of the methodology and the teacher for the student to become more involved in the subject. However, the control group teacher associated student's motivation with their personality and maturity. In this regard, Casey and Quennerstedt (2015) indicate that physical education is directly related to the generation of positive attitudes and motivation of students. However, PE as a subject will not gain the necessary prestige until teachers reach an agreement on its constituent objectives. Regarding the second variable of the study, the teacher of the experimental group indicated that it was essential that all students had a positive sense of achievement in the tasks. However, the control group teacher stated that it was impossible for all students to be able to perform all the tasks, confusing this aspect with the mark given in this subject. Experiences in this regard (Hortigüela et al., 2015) have shown how the use of open and participatory methodologies in PE produces greater student satisfaction for their learning and higher physical performance.

\section{Conclusions}

With regard to the first objective of the study, it was determined that the TGfU model had a significant impact on students' motivation in sport, also producing an increase in perspective of achievement. This shows a direct link between this methodology and a greater involvement of students in sport. With respect to the second objective, academic results significantly influenced interest in sport in group A, while differences in group $B$ were found in relation to extracurricular sports practice. This shows how students with better academic results have a better understanding of TGFU. The relationship between traditional models of sports education and extracurricular sports was also considered. Regarding the third objective, the teacher of the experimental group gave greater importance to the role that the methodology had for generating student's motivation towards physical education. She also felt that is was essential that students perceived achievement in motor tasks, while it 
was not taken into account by the PE teacher in the control group.

The main contribution of this study is evaluation of how TGfU can improve motivation and achievement perception in PE through the use of mixed methods, which is something that contributes significantly to the literature on the subject. Furthermore, it shows that the educational model used in PE determines the level of motivation. However, the study does have some limitations. First, the methodology is only implemented in one school term, so it would be interesting to develop more longitudinal studies in order to veryify TGfU's long-term effects. Secondly, the research focused on the secondary stage, thus in future it could be contrasted with the primary stage including analysis of the differences found. In addition, it could also focus on gender differences.
The present study may be of interest to all PE teachers, since sport as content is relevant in the subject and shows which methodological approach can directly influence students' motivation. Moreover, it could also be of use to public and private sports management staff in municipalities and communities, since it is essential to consider a sport teaching methodology that promotes inclusion and participation over selection and performance. It seems therefore that there is a significant need for research in the field of students' sport motivation, yet what is clear is the responsibility that PE teachers have in promoting and generating these changes.

\section{References}

Arias J, Castejón J. Using Instruments for Tactical Assessment in Physical Education and Extra-Curricular Sports. EPER, 2014; 20: 525-535

Butler J. TGfU - Would You Know It if You Saw It? Bench marks from the Tacit Knowledge of the Founders. EPER, 2014; 20: 465-488

Campbell DT. Methodology and epistemology for social science: Selected papers. Chicago: University of Chicago Press; 1988

Casey A, Quennerstedt M. "I just remember rugby": Re-membering Physical Education as More Than a Sport. Research Quarterly for Exercise and Sport, 2015; 86: 40-50

Cervelló E, Moreno JA, Del Villar F, Queen R. Development and validation of a measuring instrument of the motivational strategies in physical education classes. Iberoamerican Journal of exercise psychology and sport, 2007; 2: 53-72

Corbetta P. Methodologies and techniques of social research. Madrid: McGraw-Hill; 2007

Coulter M, Ni Chroinin D. What is PE? Sport, Education and Society, 2013; 18: 825-841

Diaz-Cueto M, Hernández JL, Castejon J. Teaching Games for Understanding to In-Service Physical Education Teachers: Rewards and Barriers regarding the Changing Model of Teaching Sport. JTPE, 2010; 29: 378-398

Hastie P, Curtner-Smith, MD. Influence of a hybrid Sport Education: Teaching Games for Understanding unit on one teacher and his students. Physical Education and Sport Pedagogy, 2006; 11: 1-27

Hastie P. Applied Benefits of the Sport Education Model. Journal of Physical Education, Recreation E Dance, 1998; 69: 24-26

Hortigüela D, Pérez-Pueyo A, Moncada J. An analysis of the responsibility of physical education students depending on the teaching methodology received. JPES, 2015; 15: 202-207

Hortigüela D, Pérez-Pueyo A, Calderón A. Effect of the model of teaching on physical self-concept of students in physical education. Retos, 2016a; 30: 76-81

Hortigüela D, Pérez-Pueyo A., Fernandez-Río J. Influence of experiences experienced by students in carrying 
out future teaching skills. Contextos educativos. Revista de Educación; 2016b; 19: 27-43

Hortigüela D, Fernández-Río J, Pérez-Pueyo A. Effects of the teaching approach in the teaching of football on the climate of the classroom. Perceptions of students and faculty. Cuadernos de Psicología del Deporte, 2016c; 16: 295-306

Hopper T. Teaching Games for Understanding: The Importance of Student Emphasis over Content Emphasis. Journal of Physical Education, Recreation \& Dance, 2002; 73: 44-48

Kirk D, MacPhail A. Teaching Games for Understanding and Situated Learning: Rethinking the BunkerThorpe Model. Journal of Teaching in Physical Education, 2002; 21: 177-192

Libarkin JC, Kurdziel JP. Research methodologies in science education: Qualitative data. Journal of Geoscience Education, 2002; 50: 195-200

Mackintosh C, Liddle J. Emerging School Sport Development Policy, Practice and Governance in England: Big Society, Autonomy and decentralization. Education, 2015; 3: 603-620

Méndez-Giménez A, Fernández-Río J, Casey A. Using the TGFU tactical hierarchy to enhance student understanding of game play. Expanding the Target Games category. CCD, 2012; 7: 135-141

Mesquita I, Farias C, Hastie P. The impact of a hybrid sport-education-invasion games competence model soccer unit on students decision making skill execution and overall game performance, European Physical Education Review, 2012; 18: 205-219

Metzler MW. Instructional Models for Physical Education (2nd ed.) Tempe, AZ: Holcomb-Hathaway; 2005

Moreno JA, Gonzalez-Cutre D, Sicilia A. Goals of achieving 2 X 2 in Spanish students of physical education. Journal of education, 2008; 347: 299-317

O'Leary N. Learning Informally to Use the "Full Version" of Teaching Games for Understanding. European Physical Education Review, 2016; 22: 3-22

Patton MQ. Qualitative Research and Evaluation Methods. Thousand Oaks, CA: Sage; 2002

Roberts SJ. Teaching Games for Understanding: the difficulties and challenges experienced by participation cricket coaches. Physical Education and Sport Pedagogy, 2011; 16: 33-48

Sanchez D, Leo FM, Amado D, Pulido JJ, Garcia-Calvo T. Analysis of motivational profiles and their relationship with the behavior of Adaptive physical education classes. Revista latinoamericana de Psicología, 2015; 47: 156-166

Siedentop D, Tannehill D. Developing teaching skills in physical education (4th edition). Mountain View, CA: Mayfield; 2005

Stolz S, Pill S. Teaching Games and Sport for Understanding: Exploring and Reconsidering its Relevance in Physical Education. EPER, 2014; 20: 36-71

Thorpe R, Bunker D, Almond L. Rethinking games teaching. Loughborough, UK: University of Technology of Loughborough; 1986

Wellard I. Body-Reflexive Pleasures: Exploring Bodily Experiences within the Context of Sport and Physical Activity. Sport, Education and Society, 2012; 17: 21-33

Wirszyla C. State-Mandated Curriculum Change in Three High School Physical Education Programs. JTPE, 2002: 22: 4-19

\section{Corresponding author:}

\section{David Hortigüela Alcalá,}

Faculty of Education, University of Burgos,

947259517 E-mail: dhortiguela@ubu.es 